\title{
A rare long QT syndrome as a cause of syncope Jervell-Lange Nielsen syndrome: case report
}

\author{
(D) Batuhan Palalıoğlu, ${ }^{1}$ (D) Rabia Çoban, ${ }^{1}$ (D) Mehmet Karacan² \\ ${ }^{1}$ Department of Pediatrics, University of Health Sciences, Ümraniye Training and Research Hospital, İstanbul, Turkey \\ ${ }^{2}$ Department of Pediatric Cardiology, University of Health Sciences, Ümraniye Training and Research Hospital, İstanbul, Turkey
}

\begin{abstract}
Congenital long QT syndrome (LQTS) is a cardiac ion channel disorder characterized by prolonged QT interval on 12-channel surface electrocardiography and Torsade de Pointes (TdP) type ventricular arrhythmia and recurrent syncope or sudden death. QTc can be prolonged due to congenital as well as acquired reasons. Ion channel disorder in acquired LQTS is due to metabolic disorder or drugs. In congenital LQTS, this disorder is caused by mutations in genes encoding ion channels in the heart muscle cell membrane. Although congenital LQTS is generally inherited as autosomal dominant, it also has an autosomal recessive form. We present a case with recurrent syncope attacks and a QTc of $540 \mathrm{~ms}$ in his electrocardiography, and congenital deafness was found to be accompanied by an autosomal recessive form of UQTS called Jervell-Lange-Nielsen Syndrome both clinically and genetically.
\end{abstract}

Keywords: Long QT syndrome; sudden death; syncope; children; Jervell-Lange-Nielsen.

Cite this article as: Karacan M, Palalığlu B, Çoban R. A rare long QT syndrome as a cause of syncope Jervell-Lange Nielsen syndrome: case report. Jour Umraniye Pediatr 2021;1(1):20-23.

ORCID ID

B.P.: 0000-0002-0106-5450; R.Ç.: 0000-0002-7854-7212; M.K.: 0000-0002-4375-2881

${ }^{1}$ Sağlık Bilimleri Üniversitesi Ümraniye Eğitim ve Araştırma Hastanesi, Çocuk Kardiyoloji Kliniği, İstanbul, Türkiye

${ }^{2}$ Sağlık Bilimleri Üniversitesi Ümraniye Eğitim ve Araştırma Hastanesi, Çocuk Sağlığı ve Hastalıkları Kliniği, İstanbul, Türkiye

Correspondence (iletişim): Dr. Mehmet Karacan. Sağlık Bilimleri Üniversitesi, Ümraniye Eğitim ve Araştırma Hastanesi,

Çocuk Kardiyoloji Kliniği, ìstanbul, Türkiye.

Phone (Tel): +90 5335678286 e-mail (e-posta): mehmet.karacan@gmail.com

(c) Copyright 2021 by Istanbul Provincial Directorate of Health - Available online at www.umraniyepediatri.com 


\section{Senkop nedeni olarak nadir görülen bir uzun QT sendromu Jervell-Lange Nielsen sendromu: Olgu sunumu}

\section{ÖZET}

Doğuştan uzun QT sendromu (UQTS) 12 kanal yüzey elektrokardiyografide QT intervalinde uzama ve "torsade de pointes (TdP)" tipi ventriküler aritmi ve tekrarlayan senkop veya ani ölümle karakterize kardiyak iyon kanalı bozukluğudur. QTc doğuştan olduğu gibi edinsel nedenlerle de uzayabilir. Edinsel UQTS'de iyon kanalı bozukluğu metabolik bozukluk veya ilaçlar nedeniyledir. Doğuştan UQTS'de bu bozukluğa kalp kası hücre membranındaki iyon kanallarını kodlayan genlerdeki mutasyonlar neden olmaktadır. Doğuştan UQTS genellikle otozomal dominant geçişli olmakla birlikte otozomal resesif geçişli formu da mevcuttur. Burada, tekrarlayan senkop atakları olan ve çekilen elektrokardiyografisinde QTc'si 550 ms saptanan, ayrıca beraberinde doğuştan sağırlı̆ı da olduğu öğrenilen hem klinik hem de genetik olarak UQTS'nin otozomal resesif formu olan Jervell-Lange-Nielsen Sendromu saptanan bir olgu sunulmuştur.

Anahtar Kelimeler: Uzun QT sendromu; ani ölüm; senkop; çocuk; Jervell-Lange Nielsen.

\section{GíRiş}

Uzun QT sendromu (UQTS), 2000 doğumda bir görülen, kalp kası hücresi aksiyon potansiyelinin repolarizasyon fazını etkileyen iyon kanallarının fonksiyon bozukluğu ile karakterize genetik bir hastalıktır (1). Hastalık genellikle asemptomatik seyretmekle beraber, semptomatik olanlarda en sık görülen senkoptur, daha seyrek de olsa ilk bulgu ani ölüm veya düzelmiş kardiyak arrest olabilir (1). Semptomatik olanların \%50'sinde 12 yaşına kadar, \%90'ında ise 40 yaşına kadar kardiyak olay ortaya çıkar (2). Kalp morfolojisinde UQTS ile ilişkili patoloji saptanmaz. Şimdiye kadar 17 alt tipi belirlenmiş olsa da hastaların yaklaşık \%90'ını tip 1, tip 2 ve tip 3 UQTS oluşturur (3). Elektrokardiyografi (EKG)'de QT uzamıştır (hıza bağlı standardizasyon için Bazett formülü ile düzeltme yapılır ve QTc olarak isimlendirilir (4) (QTc >0.44 sn) ve alt tipine göre ST-T değişikliği saptanır. "Torsade de pointes (TdP)" olarak da isimlendirilen ve UQTS görülen polimorfik ventriküler taşikardiler, kardiyak olay esnasında saptanan aritmi türüdür. Genetik geçiş sıklıkla otozomal dominant karakterde olup Romano-Ward sendromu olarak isimlendirilir. Otozomal resesif geçen formu olan Jervell-Lange-Nielsen (JLN) sendromu daha seyrek görülmekle birlikte prognozu çok daha ağır seyretmektedir (5). Bu çalışmada, otozomal dominant UQTS formuna göre çok daha seyrek görülen UQTS'nin bir formu olan ve tekrarlayan senkoplarla başvuran ve hem klinik hem de genetik olarak JLN tanısı alan bir olgu sunulmuş, doğuştan UQTS ile ilgili güncel literatür gözden geçirilmiştir.

\section{OLGU SUNUMU}

Altı yaşında erkek hasta eforla ortaya çıkan, yaklaşık beş dakika süren, beraberinde enürezis ve el-kollarda kasılmanın eşlik ettiği senkop nedeniyle dış merkez acile götürülmüş. Senkop düzeldikten sonra hastanemiz acil servisine yönlendirilmiş. Hasta acile geldiğinde bilinci açık, vital bulguları stabil (kan basıncı 90/50 $\mathrm{mmHg}$, oda havasında oksijen satürasyonu \%99, kalp tepe atımı 105 atım/dakika), solunum sesleri doğal ve kardiyak muayenesinde özellik saptanmamıştır. Hastanın anamnezinde daha önce de iki defa eforla (oynarken ve merdiven çıkarken) ortaya çıkan ve benzer özellikler gösteren senkoplarının olduğu; hasta- nın ayrıca doğuştan sağırlığının olması nedeniyle işitme cihazı kullandığı da öğrenilmiştir. Hastanın çekilen EKG'sinde QTc değerinin 550 ms olduğu saptanmıştır (Şekil 1). Kan biyokimya ve hemogram normal bulunmuştur. QTc uzatacak ilaç alma öyküsü tespit edilmemiştir. EKG'de QTc 500 ms'nin üzerinde olması ve tekrarlayan senkop atakları olması sebebiyle doğuştan sensörinöral sağırlığı olan hastaya klinik olarak JLN sendromu tanısı ko-

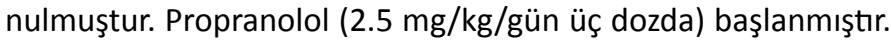
Hastanın 22 kg olması ve transvenöz ICD için kilosunun yetersiz olması sebebiyle epikardiyal yöntemle ICD impantasyonu yapılmıştır. Genetik analiz için kan örneği gönderilmiştir. Genetik sonucu KCNQ1 geninde homozigot mutasyon (c.1097G>A) saptanarak kesin tanı konulmuştur. İzlemde tedaviye rağmen doğru şokları olması üzerine sol kardiyak sempatik denervasyon işlemi yapılmıştır. İşlem sonrası takiplerinde şok öyküsü olmamıştır. Hastaya genetik tanı konulduktan sonra önce aile bireyleri, daha sonra da anne ve babanın kardeşleri genetik taramadan geçirilmiş, başta kardeşi ve anne-babası olmak üzere çok sayıda yakınında heterozigot formda aynı mutasyon saptanmıştır.

\section{TARTIŞMA}

Uzun QT sendromunun konjenital formunda kalp kası hücresindeki iyon kanallarında iyon hareketini düzenleyen genlerde

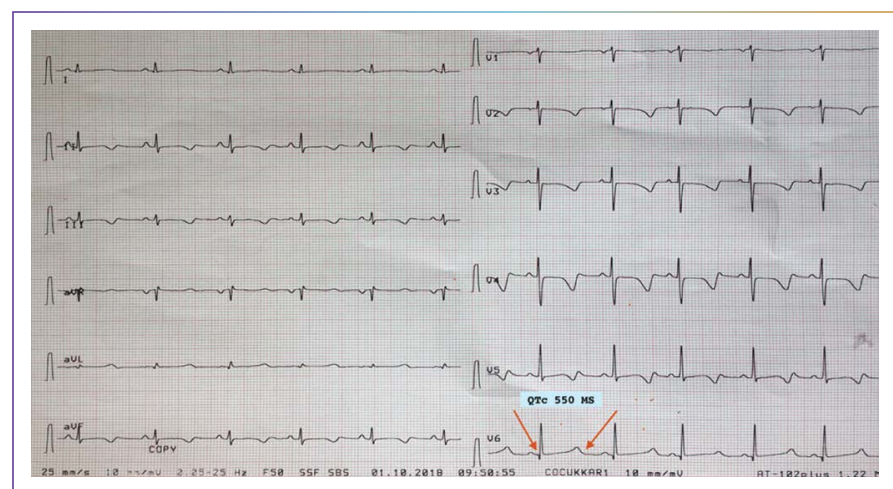

Şekil 1. Hastanın 12 kanal yüzey elektrokardiyografisinde uzamış QTc değeri (QTc= $550 \mathrm{~ms}$ ). 
mutasyon söz konusudur. Mutasyon sonucu kalp kası hücresinin iyon hareketlerindeki (özellikle $\mathrm{K}$ ve $\mathrm{Na}$ ) değişiklikler sonucu aksiyon potansiyeli genişlemekte ve kalp kası hücresinin repolarizasyonu uzamaktadır. Bu değişiklikler EKG'ye QT uzaması olarak yansır. Şimdiye kadar UQTS'den sorumlu 15 otozomal dominant (Romano-Ward sendromu), iki de otozomal resesif gen saptanmış olup, hastaların \%85'ini tip 1, 2 ve 3 oluşturur (3). Otozomal dominant form UQTS 2000 doğumda 1 görülürken, otozomal resesif formu olan JLN sendromunun 200.000 kişide 1 görüldüğü saptanmıştır $(6,7)$.

Hastalar özellikle sempatik aktivitenin arttı̆̆ egzersiz veya duygusal uyarım durumlarında, yaşamı tehdit edici ventrikül aritmilerine karşı hassas durumdadırlar. UQTS'nin başlıca semptomu TdP tipi ventriküler taşikardiden kaynaklanan senkoptur. Çoğunlukla TdP kendi kendine sonlanır ve hasta çabucak kendine gelir (senkop). Bazen de TdP uzun süreli olur ve kardiyopulmoner canlandırma işlemi uygulanmazsa ritim geri dönmeyebilir.

Uzun QT sendromunda ventriküler aritmileri tetikleyen faktörler saptanmıştır: Tip 1 UQTS egzersizle, tip 2 UQTS duygusal etkilenimle, tip 3 UQTS ise genellikle uykuda, efordan bağımsız kardiyak olay olarak ortaya çıkar (8). Otozomal resesif formu olan JLN sendromunda hastalar genellikle semptomatik olduklarından ve doğuştan sağırlık eşlik ettiğinden tanı konulması otozomal dominant formlarına göre daha kolaydır. Bununla birlikte her iki geçiş formunda da kardiyak olayı engellemek için tetikleyen faktörleri bilmek önemlidir.

Uzun QT sendromu tanısının, 2013 yılında yayınlanan rehbere göre; QTc'yi uzatacak ilaç almamasına rağmen QTc değerinin tekrarlayan 12 kanal EKG'de 500 ms ve üzerinde saptanması veya skorun 3.5 ve üzerinde olmasıyla veya UQTS'ye neden olan patojenik mutasyon saptanmasıyla konulabileceği bildirilmiştir. Aynı rehbere göre daha az kesinlikte olmakla birlikte yine “QTc'yi uzatan ilaç almamasına rağmen seri 12 kanal EKG ölçümlerinde QTc değerinin 480-499 ms arasında olması" da UQTS tanısını koydurmaktadır (9).

Uzun QT sendromu tanısı için Schwartz ve arkadaşları tarafindan tanıda kullanılmak üzere daha önce belirlenen kriterler en son 2011 yılında güncellenmiştir. Kriterlerden alınan puanın 3.5 ve üzerinde olması, tanıda yeterli sayılmıştır (10). Bu skorlama sisteminin asemptomatik hastalarda duyarlılığı oldukça düşük saptanmıştır (11).

Elektrokardiyografide QT değerini standardize etmek için kullanılan Bazett formülüne göre QTc değerinin erkeklerde 450 ms, kadınlarda 460 ms ve üzerinde olması patolojik kabul edilmiştir. UQTS olan hastaların bir kısmında QTc değerlerinin patojenik değerin üzerine çıkmadığı saptanmıştır. QTc değerleri özellikle sınırda yüksek olan hastalarda efor veya adrenalin provokasyon testi tanıya daha çok yaklaştırır (12).

Uzun QT sendromunda genetik analiz hem kesin tanı konulmasında hem de tedavide risk belirlemenin bir parçası olmaya başlamıştır. Bununla birlikte hastaların genetik olarak sadece \%8085'ine tanı konulmaktadır (3). Bu nedenle genetik çalışmanın, UQTS'de bir tarama metodu olarak değil, klinik olarak tanı almış veya ısrarla 480 ms ve üzerinde QTc değeri olan hastalarda kul- lanılması gereklidir. Genetik çalışma ayrıca asemptomatik aile bireylerini saptamak için de gereklidir. Bu hastada KCNQ1 geninde homozigot patojenik mutasyon saptanmıştır. Anne ve babanın da aynı geni heterozigot olarak taşıdığı; anne ve babanın çok sayıda kardeşinde ve kardeş çocuklarında da benzer mutasyon olduğu tarama ile saptanmış ve tedavileri düzenlenmiştir.

Tedavide senkop ve ani ölüme neden olabilen ventriküler aritmilerin önlenmesi amacıyla efor ve/veya emosyonel stres gibi uyarıcı faktörlerden uzak durmak çok önemlidir. Bunun yanında medikal tedavi olarak beta-bloker altın standart tedavi kabul edilmekte olup, tüm beta-blokerlerin benzer etki göstermediği, özellikle nadolol ve propranololün tedavide etkili oldukları saptanmıştır (13). Meksiletin, bazı tip 3 UQTS hastalarında QTc değerini belirgin kısalttğı ve kardiyak olayları azalttğı saptanmış olduğundan bu grup hastada tedaviye eklenmektedir. Tüm bu tedavilere rağmen kardiyak olay riski bazı hastalarda devam etmekte olup, QTc değeri 500 ms ve üzerinde olması gibi bazı kriterlerin varlığında; bunun yanında kardiyak arrest geçiren hastalarda medikal tedaviye ilaveten ICD takmak ani ölümü önlemek açısından önemlidir (14). Buradaki olgu hem tekrarlayıcı senkop ataklarının olması hem de QTC değerinin 550 ms olması nedeniyle yüksek riskli kabul edilip, olguya epikardiyal ICD takılmıştır.

Ayrıca optimal tedaviye rağmen sık kardiyak olay geçiren hastalarda videoskopik yöntemle yapılan sol kardiyak sempatik denervasyonun kardiyak olay sıklığını belirgin azalttı̆̆ gösterilmiştir (15). Optimal tedaviye rağmen kardiyak olay gelişebilmektedir. Bu çalışmadaki hastanın tedavide aksama olmamasına rağmen izlemde tekrarlayıcı şoklar verdiği, ICD incelendiğinde de şokları doğru verdiği saptanmıştir. Bunun üzerine hastaya sempatektomi yapılmıştır. Sempatektomi sonrası 1.5 yıldır izlemi yapılan hastada daha sonra kardiyak olay gelişmemiştir.

\section{SONUÇ}

Efor veya emosyonel stres ile ortaya çıkan senkopların ayırıcı tanısında mutlaka doğuştan UQTS düşünülerek yüzey EKG'de QTc dikkatle değerlendirilmelidir. Yalnız EKG kontrolü ile olguların büyük bir kısmında tanı konulduğu gibi genotip tayini yapmak da mümkündür. JLN sendromu UQTS'ler içinde ani ölüm yönünden en yüksek riskli tiplerden biridir. Bu hastalarda erken tanı konulması, ani ölümün önlenmesi yönünden önemlidir. UQTS saptanan hastalarda genetik çalışma, hem yüksek risk belirlenmesinde hem tedavi seçiminde hem de asemptomatik aile bireylerini taramada önemlidir.

Hasta Onamı: Olgu sunumu ve beraberindeki görüntülerin yayınlanması için hastadan yazılı bilgilendirilmiş onam alındı.

Çıkar Çatışması: Yazarlar çıkar çatışması bildirmemişlerdir.

Mali Destek: Yazarlar bu çalışma için mali destek almadıklarını beyan etmişlerdir.

Yazarlık Katkıları: Fikir - M.K.; Tasarım - M.K., B.P., R.Ç.; Denetmele - M.K.; Kaynaklar - R.Ç., B.P.; Yazıyı Yazan - B.P., R.Ç., M.K.; Eleştirel Inceleme - M.K.

Informed Consent: Written informed consent was obtained from the 
patient for the publication of the case report and the accompanying images.

Conflict of Interest: No conflict of interest was declared by the authors.

Financial Disclosure: The authors declared that this study has received no financial support.

Authorship Contributions: Concept - M.K.; Design - M.K., B.P., R.C..; Supervision - M.K.; Literature review - R.Ç., B.P.; Writing - B.P., R.Ç., M.K.; Critical review - M.K.

\section{KAYNAKLAR}

1. Moss AJ, Schwartz PJ, Crampton RS, Tzivoni D, Locati EH, MacCluer J, et al. The long QT syndrome. Prospective longitudinal study of 328 families. Circulation 1991;84(3):1136-44. doi: 10.1161/01. cir.84.3.1136

2. Zareba W, Moss AJ, Schwartz PJ, Vincent GM, Robinson JL, Priori $S G$, et al. Influence of the genotype on the clinical course of the long-QT syndrome. International Long-QT Syndrome Registry Research Group. N Engl J Med 1998;339(14):960-5. doi: 10.1056/ NEJM199810013391404

3. Tester DJ, Will ML, Haglund CM, Ackerman MJ. Compendium of cardiac channel mutations in 541 consecutive unrelated patients referred for long QT syndrome genetic testing. Heart Rhythm 2005;2(5):507-17. doi: 10.1016/j.hrthm.2005.01.020

4. Bazett HC. An analysis of the time-relations of electrocardiograms. Heart 1920;7:35-70.

5. Schwartz PJ, Spazzolini C, Crotti L, Bathen J, Amlie JP, Timothy K, et al. The Jervell and Lange-Nielsen syndrome: natural history, molecular basis, and clinical outcome. Circulation 2006;113(6):783-90. doi: 10.1161/CIRCULATIONAHA.105.592899

6. Schwartz PJ, Stramba-Badiale $M$, Crotti L, Pedrazzini $M, B e-$ sana A, Bosi $G$, et al. Prevalence of the congenital long-QT syndrome. Circulation 2009;120(18):1761-7. doi: 10.1161/ CIRCULATIONAHA.109.863209

7. Winbo A, Stattin EL, Diamant UB, Persson J, Jensen SM, Rydberg A. Prevalence, mutation spectrum, and cardiac phenotype of the Jervell and Lange-Nielsen syndrome in Sweden. Europace
2012;14(12):1799-806. doi: 10.1093/europace/eus111

8. Schwartz PJ, Priori SG, Spazzolini C, Moss AJ, Vincent GM, Napolitano $C$, et al. Genotype-phenotype correlation in the long-QT syndrome: gene-specific triggers for life-threatening arrhythmias. Circulation 2001;103(1):89-95. doi: 10.1161/01.cir.103.1.89

9. Priori SG, Wilde AA, Horie M, Cho Y, Behr ER, Berul C, et al. HRS/ EHRA/APHRS expert consensus statement on the diagnosis and management of patients with inherited primary arrhythmia syndromes: document endorsed by HRS, EHRA, and APHRS in May 2013 and by ACCF, AHA, PACES, and AEPC in June 2013. Heart Rhythm 2013;10(12):1932-63. doi: 10.1016/j.hrthm.2013.05.014

10. Schwartz PJ, Crotti L. QTc behavior during exercise and genetic testing for the long-QT syndrome. Circulation 2011;124(20):2181-4. doi: 10.1161/CIRCULATIONAHA.111.062182

11. Priori SG, Schwartz PJ, Napolitano C, Bloise R, Ronchetti E, Grillo $\mathrm{M}$, et al. Risk stratification in the long-QT syndrome. N Engl J Med 2003;348(19):1866-74. doi: 10.1056/NEJMoa022147

12. Sy RW, van der Werf C, Chattha IS, Chockalingam P, Adler A, Healey JS, et al. Derivation and validation of a simple exercise-based algorithm for prediction of genetic testing in relatives of LQTS probands. Circulation 2011;124(20):2187-94. doi: 10.1161/circulationaha.111.028258.

13. Abu-Zeitone A, Peterson DR, Polonsky B, McNitt S, Moss AJ. Efficacy of different beta-blockers in the treatment of long QT syndrome. J Am Coll Cardiol 2014;64(13):1352-8. doi: 10.1016/j. jacc.2014.05.068

14. Zareba W, Moss AJ, Daubert JP, Hall WJ, Robinson JL, Andrews M. Implantable cardioverter defibrillator in high-risk long QT syndrome patients. J Cardiovasc Electrophysiol 2003;14(4):337-41. doi: 10.1046/j.1540-8167.2003.02545.x

15. Schwartz PJ, Priori SG, Cerrone M, Spazzolini C, Odero A, Napolitano $C$, et al. Left cardiac sympathetic denervation in the management of high-risk patients affected by the long-QT syndrome. Circulation 2004;109(15):1826-33. doi: 10.1161/01. CIR.0000125523.14403.1E 